\title{
Vaccinia Virus Outperforms a Panel of Other Poxviruses as a Potent Oncolytic Agent for the Control of Head and Neck Squamous Cell Carcinoma Cell Lines
}

\author{
Anthony C. Nichols ${ }^{a}$, b, d, e John Yoo a, b, d Sung Um ${ }^{a}$ Neil Mundi ${ }^{a}$ \\ David A. Palma ${ }^{b, d, e}$ Kevin Fung ${ }^{a, b}, d$ S. Danielle MacNeil ${ }^{a, b}, d$ \\ James Koropatnick $^{\mathrm{b}-\mathrm{e}}$ Joe S. Mymryk ${ }^{\mathrm{b}-\mathrm{e}}$ John W. Barrett ${ }^{\mathrm{a}}$, e \\ Departments of a Otolaryngology Head and Neck Surgery, ${ }^{b}$ Oncology, and ${ }^{~}$ Microbiology and Immunology, Western \\ University, ${ }^{\mathrm{d}}$ London Regional Cancer Program, and ${ }^{\mathrm{E}}$ Lawson Health Research Institute, London, Ont., Canada
}

\section{Key Words}

Head and neck squamous cell carcinoma · Poxvirus .

Oncolytic $\cdot$ Myxoma $\cdot$ Tanapox particularly vaccinia virus, were effective in killing HNSCC in vitro and hold promise as potential treatments for patients with HNSCC.

Copyright $\odot 2013$ S. Karger AG, Basel

\begin{abstract}
Background: Head and neck squamous cell carcinoma (HNSCC) is the fifth most common cancer worldwide. Existing therapies for advanced tumors have high failure rates and can have severe consequences in terms of pain, disfigurement, and poor speech and swallowing function. New treatment strategies are needed to improve outcomes for patients suffering with this disease and oncolytic viruses represent a promising approach. Methods: We infected six wellcharacterized HNSCC cell lines (Cal27, Detroit562, FaDu, SCC4, SCC15, SCC25), with increasing doses of a panel of poxviruses (including myxoma, vaccinia, raccoonpox and tanapox viruses) modified to express green fluorescence protein to determine which virus was the most effective oncolytic agent in cell-based assays. Results: While myxoma, raccoonpox and tanapox displayed differing efficacy in the panel of cell lines, vaccinia virus was the most potent of the tested poxviruses and was highly effective in controlling cell growth in all cell lines. Conclusion: Oncolytic poxviruses,
\end{abstract}

\section{Introduction}

Head and neck squamous cell carcinoma (HNSCC) is the fifth most common cancer worldwide, with 650,000 new cases per year [1]. Greater than $50 \%$ of these patients present with locally advanced disease, associated with 5 -year overall survival rates ranging from 40 to $60 \%$, underscoring an urgent need for improvement [1]. Contemporary treatment strategies involve primary radiation and/or surgery, which may cause marked morbidity including pain, disfigurement, and poor speech and swallowing outcomes. Novel treatments are needed to improve survival rates and quality of life outcomes for patients suffering with this disease.

An emerging strategy is the use of replication competent oncolytic viruses to selectively infect tumors while sparing normal tissue. Oncolytic virotherapy involves the use of naturally occurring or engineered viruses that dis-

\section{KARGER}

E-Mail karger@karger.com

www.karger.com/int
(C) 2013 S. Karger AG, Basel

0300-5526/14/0571-0017\$39.50/0
Drs. John Barrett and Anthony Nichols

Victoria Hospital, London Health Science Centre

Department of Otolaryngology - Head and Neck Surgery, Room B3-431A

800 Commissioners Road East, London, ON N6A 5W9 (Canada)

E-Mail john.barrett@lhsc.on.ca; anthony.nichols@lhsc.on.ca 
play selectivity for one or more types of cancer. A number of poxviruses, particularly vaccinia virus, which exhibits a broad host range and the rabbit-specific myxoma virus, have demonstrated efficacy in vitro as well as clinical responses in early phase oncolytic studies [2,3]. Raccoonpox virus has also been shown to significantly slow tumor progression and increase survival in both xenograft and syngeneic models of solid tumors in mice [4]. Although it seems likely that most poxviruses are capable of entering nearly all cell types and initiating viral protein synthesis, completion of viral replication and/or morphogenesis does not necessarily occur in all host cell types, thereby defining viral tropism [5]. As well, the mechanisms employed by poxviruses to enter and infect human cancer cells can be different, suggesting that there may be multiple strategies exploited by other poxviruses as oncolytics [6].

It is likely that no single virus will provide optimal therapy for every patient given the response rates of approximately $30 \%$ or less to individual viruses that have been observed [2]. Clinical trials, testing a range of viruses, including adenovirus, reovirus and herpesvirus, to control HNSCC are underway [2]. However, outside of tests with vaccinia virus, the poxvirus family of viruses has not been characterized for oncolytic activity in HNSCC $[7,8]$.

We have initiated in vitro studies on the ability of four different poxviruses, from three genera of the family Poxviridae, to control a panel of HNSCC cell lines to determine the spectrum of efficacy of each virus within each cell line. This strategy will allow us to select promising candidate(s) to test in preclinical models animal models and exclude less effective viruses.

\section{Methods}

Cell Culture Conditions and Viruses

HNSCC cell lines SCC4, SCC15, SCC25, FaDu, Cal27 and Detroit562, as well the control cell lines Vero and owl monkey kidney (OMK) cells, which acted as non-cancerous controls, were obtained from the ATCC. We have previously confirmed the identity of these HNSCC cell lines by short tandem repeat profiling [9]. All cell lines were grown in DMEM/F12 supplemented with $10 \%$ FBS (Gibco), $400 \mathrm{ng} / \mathrm{ml}$ hydrocortisone (Wisent) and penicillin $(100 \mathrm{IU} / \mathrm{ml})$ and streptomycin $(100 \mu \mathrm{g} / \mathrm{ml})$ (Invitrogen). The green fluorescence protein (GFP) tagged vaccinia (VACV, vaccine strain Copenhagen), raccoonpox (RCNV, strain feline-derived), tanapox (TANV, strain Kenya-1950) and myxoma (MYXV, strain Lausanne) viruses employed in this study have been described previously [4, 10-12]. VACV, TANV and MYXV were generously supplied by Dr. G. McFadden, University of Florida, Gainesville, Fla., USA. GFP was cloned under the synthetic early/late poxviral promoter which allowed us to visualize virus entry and virus replica- tion $[4,10-12]$. As a negative control for infection in all experiments, we generated a UV-inactivated vaccinia virus (UV-VACV). One milliliter of the parental vaccinia virus stock was subjected to direct UV light for $60 \mathrm{~min}$. The UV-treated virus was titrated back onto permissive Vero cells to confirm the inactivation of vaccinia virus. The titer was reduced $10^{6}$-fold.

\section{Evaluation of Infectivity}

Cells were seeded $\left(4 \times 10^{4}\right)$ into each well of a 48 -well dish. After $24 \mathrm{~h}$ when the cells had reached a confluence of $85-90 \%$, virus was added at multiplicity of infection (MOI) of $3,0.3,0.03$ or 0 (uninfected). Virus was allowed to adsorb for $1 \mathrm{~h}$ at $37^{\circ}$ and then the inoculum was removed. Cells were then washed and medium was replaced. Cells were evaluated at $24,48,72$ and $96 \mathrm{~h}$. The presence of fluorescence indicated viral entry and expression of the GFP transgene. Plaque and focus formation and morphology indicated cell death and virus spread.

Virus Amplification Kinetics

HNSCC cells were seeded into 6 -well dishes $\left(6 \times 10^{5}\right.$ cells/well $)$ and infected at an MOI of 5 . Infected cells were collected at the times zero and $48 \mathrm{~h}$ postinfection (hpi). Virus was released from the collected cell pellets by three freeze/thaw cycles and titrated back onto permissive Vero (RCNV, VACV, MYXV and UV-VACV) or OMK (TANV) cells. Fluorescent foci were scored $48 \mathrm{hpi}$ and these values were used to calculate virus amplification.

\section{Proliferation Assay}

Cells were seeded $\left(4 \times 10^{3}\right)$ into each well of a 96-well dish. After $24 \mathrm{~h}$ when the cells had reached $85-90 \%$ confluence, cells were left uninfected or virus was added and allowed $1 \mathrm{~h}$ to adsorb at $37^{\circ}$ at an MOI of $0.03,0.3$ or 3 . At $24,48,72$ and 96 h, Presto Blue reagent (10 $\mu \mathrm{l} /$ well; Invitrogen) was added to 3 wells for each MOI and then incubated at $37^{\circ}$ for $30 \mathrm{~min}$. Fluorescence was quantified by fluorimetry.

\section{Results}

\section{Virus Tropism}

Of the poxvirus family of viruses, only VACV has been characterized for oncolytic activity in HNSCC $[7,8]$. To begin comparisons of the oncolytic abilities of different poxviruses, we first determined the ability of four different poxviruses (MYXV, VACV, RCNV and TANV) to infect six well-characterized HNSCC lines. Each virus was engineered to express a GFP transgene, allowing a visual analysis of the progress of infection.

GFP expression was confirmed from all viruses by fluorescent microscopy. At low multiplicities of infection $(\mathrm{MOI}=0.3$ and 0.03$)$, viruses produced plaques (RCNV and VACV) or foci of infection (MYXV and TANV). As expected, there was no visual evidence of GFP expression using UV-inactivated VACV (UV-VACV) in any of the cell lines (data not shown). 


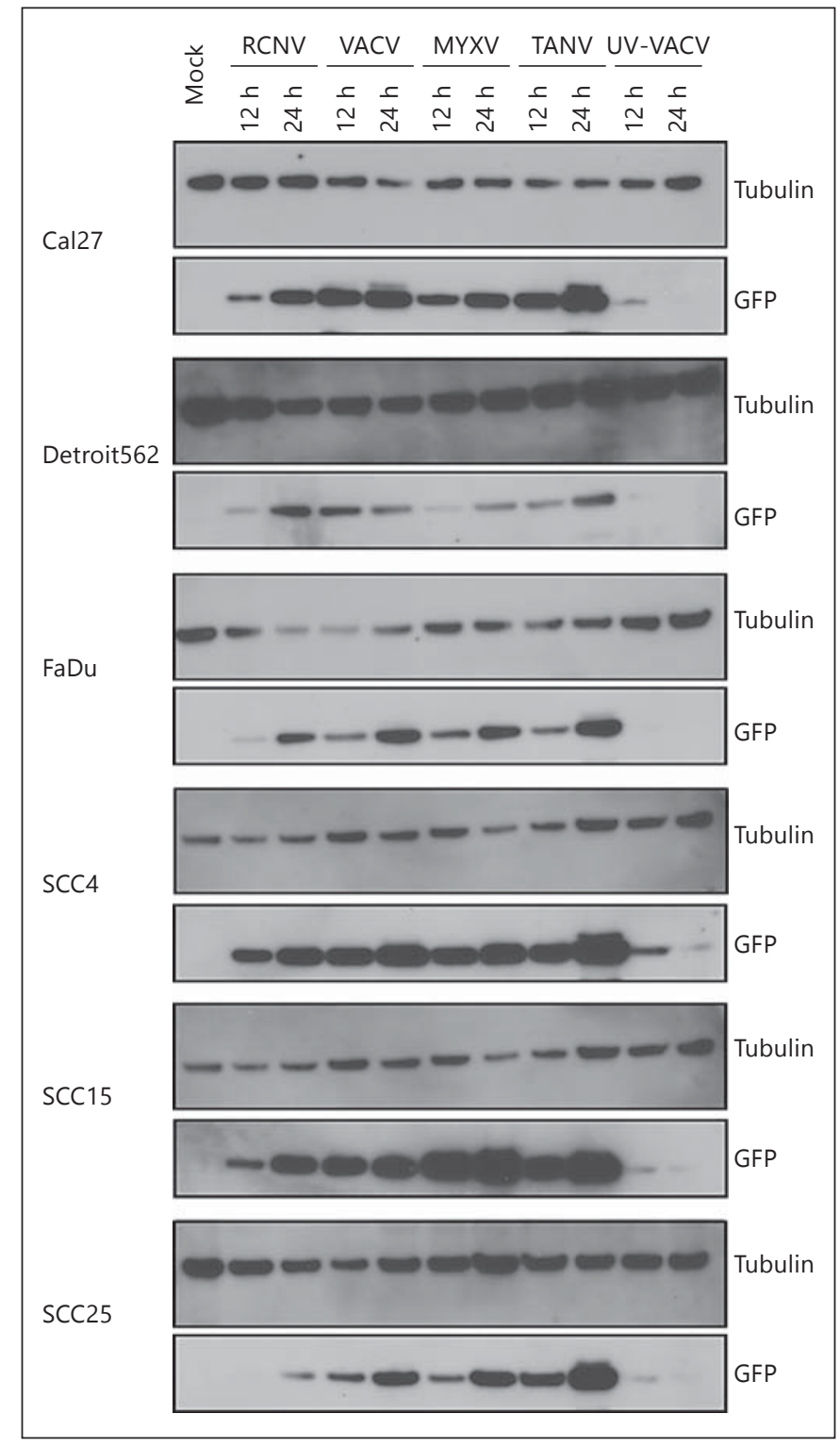

Fig. 1. GFP was expressed in HNSCC cell lines following infection with vaccinia virus (VACV), raccoonpox virus (RCNV), tanapox virus (TANV), myxoma virus (MYXV) or UV-inactivated VACV (UV-VACV). Each cell line was left either uninfected or was infected with one of the indicated viruses. Infected cells were collected at 12 and $24 \mathrm{hpi}$ and whole cell lysates were prepared. Membranes were probed with anti-GFP antibody and then stripped and probed again with anti-tubulin antibody.

Western blot analysis confirmed that GFP accumulated in the cell lines and that levels of GFP generally increased in intensity over time postinfection (fig. 1). In contrast, little or no GFP was observed from the UV-VACV samples, confirming UV light damage to the control viruses (fig. 1,
Table 1. Productive virus increase over time

\begin{tabular}{lllll}
\hline \multirow{2}{*}{ Name } & \multicolumn{3}{l}{$\log$ increase over $48 \mathrm{~h}$} & \\
\cline { 2 - 5 } & RCNV & VACV & MYXV & TANV $^{1}$ \\
\hline Cal27 & $1^{2}$ & 3 & 1 & 1 \\
Detroit562 & 0 & 2 & 0 & 0 \\
FaDu & 2 & 2 & 1 & 1 \\
SCC4 & 1 & 1 & 0 & 1 \\
SCC15 & 1 & 2 & 2 & 1 \\
SCC25 & 2 & 2 & 1 & 0 \\
\hline
\end{tabular}

${ }^{1}$ Virus collected from the indicated HNSCC cell lines were titrated on Vero cells except for TANV which was titrated on OMK cells.

${ }^{2}$ Numbers indicate the log increase between the input virus following $1 \mathrm{~h}$ adsorption and replication $48 \mathrm{hpi}$. For example, the titer of RCNV did not increase over $48 \mathrm{~h}$ from the input virus in Detroit562. In contrast, VACV increased 100-fold (log increase $=$ 2 ) over the same time and in the same cell line.

last lanes for each blot). Blots were stripped and probed with anti-human tubulin to confirm equal loading of samples (fig. 1). In most cases (Cal27, FaDu, SCC4, SCC15, and SCC25 but not Detroit562) the level of GFP expression increased from 12 to $24 \mathrm{~h}$ indicating the accumulation of protein following viral late gene expression and indirectly demonstrating the ability of the viruses to replicate in these cells. In contrast to VACV, MYXV and TANV, GFP expression from RCNV-infected $\mathrm{FaDu}$ and SCC25 cells appeared to be delayed. The levels of tubulin suggested that this lower GFP level at 12 hpi for RCNV was not the result of lower overall total protein, suggesting an initial restriction to gene expression that was overcome with time. As well, there was a general increase in GFP expression from 12 to 24 hpi evident in all VACV-infected cells except for VACVinfected Detroit562 cells. The total protein levels were comparable, indicating that the decrease represents a true reduction in the accumulation of GFP protein, contrary to what is observed for all the other viruses.

\section{Replication Kinetics}

To measure the ability of this panel of experimental poxviruses to enter and replicate in the HNSCC lines, we measured the increase in infectious virus between input viral titer and virus production at $48 \mathrm{hpi}$ (table 1). It was clear that the viruses were able to enter the cell, replicate and produce infectious progeny virus, although there was substantial variation in the level of production. For example, RCNV produced infectious virus progeny regard- 
Fig. 2. Poxvirus infection affected cell viability. Cal27 (black bars), Detroit562 (light grey bars), FaDu (dark grey bars), SCC4 (white bars), SCC15 (hatched bars) and SCC25 (stippled bars) were infected at an MOI $=5$ and then monitored for changes in cell viability using PrestoBlue (Invitrogen) at 96 hpi. Fluorescence values (relative fluorescence units; RFU), as a measure of cell numbers were compared against the uninfected controls and blanks to determine the percent metabolic activity and converted to percent survival/proliferation against the controls and plotted on the $\mathrm{Y}$ axis. The $\mathrm{X}$-axis represents the viruses. Virus abbreviations are as noted in figure 1 legend.

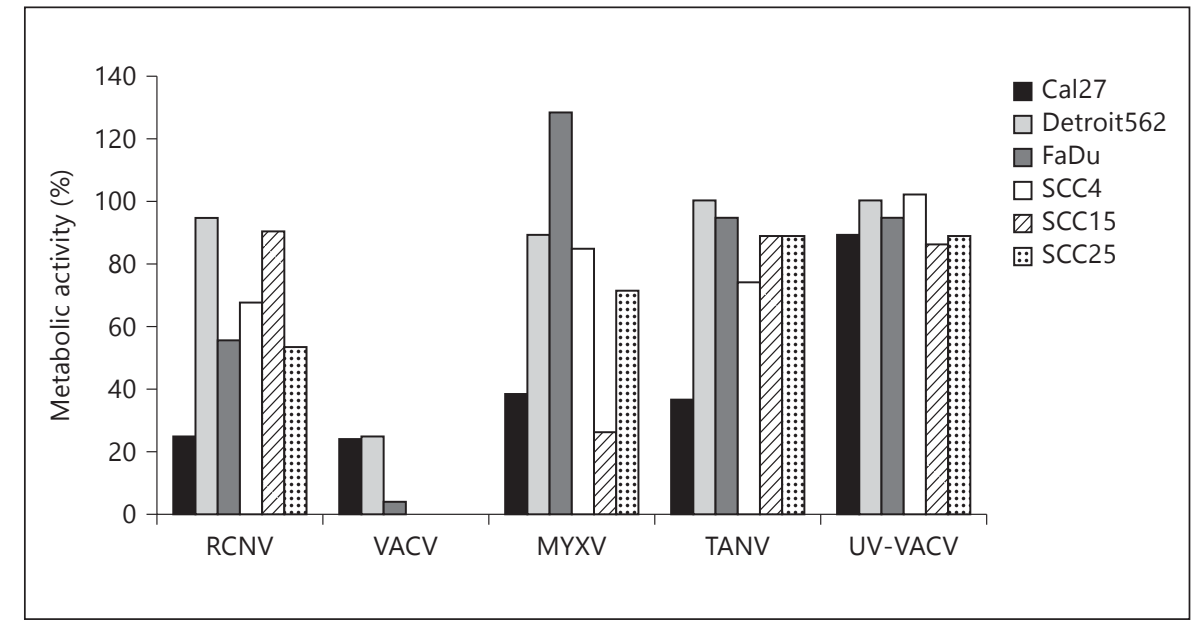

less of the cell line (table 1). However, there was less than a single-log increase in Detroit562 cells. In contrast, the viral titers of VACV increased by at least 1-log (SCC4) to 3-logs (Cal27). We observed variable increases of MYXV and TANV virus (table 1). There was no measurable infectious virus at input or $48 \mathrm{hpi}$ for the control UV-inactivated virus (data not shown). All viruses were able to form productive infections in all cell lines, with the exception of Detroit562 in which only VACV was able to form an infection in which substantial virus amplification occurred.

\section{Poxviruses Demonstrate Differential Killing of HNSCC Cell Lines}

To determine the relative ability of the different poxviruses to control the growth and spread of HNSCC cells, we set up a viability assay to monitor the metabolic activity of each of the HNSCC cell lines upon infection. Cells were left uninfected or infected with one of the experimental poxviruses or the UV-inactivated control at a range of MOIs (0.05-5). We measured cell viability every $24 \mathrm{~h}$ for up to $96 \mathrm{~h}$ and found that Cal27 was the most susceptible to all the poxviruses tested and that Detroit562 was the least susceptible to virus-mediated suppression of tumor cell proliferation/survival (fig. 2, compare black bars (Cal27) versus light grey bars (Detroit562)). Generally the greatest suppression of cancer cell survival/proliferation was seen at the highest MOI (=5) at the $96 \mathrm{hpi}$ time point for all poxviruses (fig. 2). VACV exhibited the best control of cellular proliferation as measured by PrestoBlue. The other viruses demonstrated varying efficacy in different lines. For example, MYXV effectively controlled Cal27 (60\% reduction) and SCC15 (70\% reduction); TANV was effective only in Cal27 (62\% reduction), and $\mathrm{RCNV}$ was most effective in Cal27 (75\% reduction), but also moderately effective in $\mathrm{FaDu}$ (45\% reduction) and SCC25 (45\% reduction) (fig. 2). These results indicate that the different poxviruses clearly differ in their ability to kill across this spectrum of HNSCC cells.

The high levels of VACV oncolytic activity, as measured by these assays in all six HNSCC lines, occurred in a time- and MOI-dependent manner (fig. 3). At an MOI = 3 (dark grey bars), VACV reduced SCC15 cell viability by approximately $80 \%$ at $24 \mathrm{~h}$ (fig. 3). The viability of SCC4, SCC15 and SCC 25 was greatly reduced by $48 \mathrm{hpi}$, and no remaining viable cells for these lines were detected at 96 hpi (fig. 3). Nevertheless, there was some variation in the sensitivity of cells to VACV. For example, VACV was effective in $\mathrm{Cal} 27, \mathrm{FaDu}, \mathrm{SCC} 4$ and SCC25 at an MOI $=0.03$ by $96 \mathrm{hpi}$, but was only moderately effective in SCC15 at the lowest MOI and ineffective in Detroit562 at the same MOI (fig. 3, bottom panel).

\section{Discussion}

Novel therapies are urgently needed for head and neck cancer treatment. Current management strategies involving surgery, radiation and chemotherapy can have devastating consequences on patient quality of life including disfigurement, pain and the inability to eat or speak. This combined with poor survival rates demands new treatment options.

Generally we did not observe a correlation between virus amplification, following replication, and cell viability. For example, all poxviruses proved equally effective at reducing the cell proliferation of Cal27 cells by $65-75 \%$ 
(fig. 2). However, only VACV exhibited a vigorous amplification of the virus in these cells, increasing by 3 logs (table 1). In contrast, although RCNV replicated as well as VACV in several cell lines (FaDu, SCC4 and SCC25), as measured by virus amplification (table 1), the ability of RCNV to control cellular proliferation was much poorer. For example, FaDu cell proliferation was reduced by $43 \%$ following treatment with RCNV, while VACV reduced FaDu cell proliferation by $97 \%$ (fig. 2 ). The exception to the lack of correlation was the Detroit562 cell line. None of the viruses except VACV were able to produce a productive infection in Detroit562 (table 1) and this lack of virus replication was correlated with an inability (except for VACV) to reduce Detroit562 proliferation (fig. 2).

There is mounting evidence that poxviruses, particularly vaccinia virus, may be ideal oncolytic agents. Poxviruses are particularly attractive as: (1) their large size may cause them to preferentially deposit in tumors due to increased permeability of the tumor vasculature; (2) they replicate and lyse cells rapidly; (3) have broad tissue tropism; (4) they do not integrate into the host cell genome, and (5) they are very stable in the blood, allowing intravenous delivery and spread of the virus to sites of distant metastases [13]. As well, poxviruses can exhibit very speciesrestricted host range and many will not productively infect humans (e.g. myxoma virus and raccoonpox virus). Vaccinia has the advantage of a long history of safety in humans as the vector for the smallpox vaccine. VACV strain Copenhagen, was the vaccine strain used in Northern Europe during the smallpox eradication campaign. A thymidine kinase gene deleted version of VACV Copenhagen, tested as an oncolytic vector in human colorectal tumors, has been shown to have good tumor selectivity and effectively retard tumor growth in nude mice [14]. The best studied oncolytic VACV strain is a modified version of the Wyeth strain, JX-594, which has shown promising results in metastatic cancer [2]. MYXV, RCNV and TANV have all demonstrated oncolytic activity in various preclinical models $[4,11,12]$ and do not cause infection in normal human tissue with the exception of tanapox virus which can produce a localized, limited infection [12]. Although numerous investigators have studied a variety of oncolytic viruses including various strains of vaccinia virus $[7,15$, 16], this is the first evaluation of a panel of poxviruses for the control of head and neck cancer.

Early clinical trials of oncolytic poxvirus have produced impressive partial and complete responses in a variety of cancers, however these occur in $30 \%$ or less of cases [2]. These variable responses may represent viral discrimination created by tumor-specific signaling path-

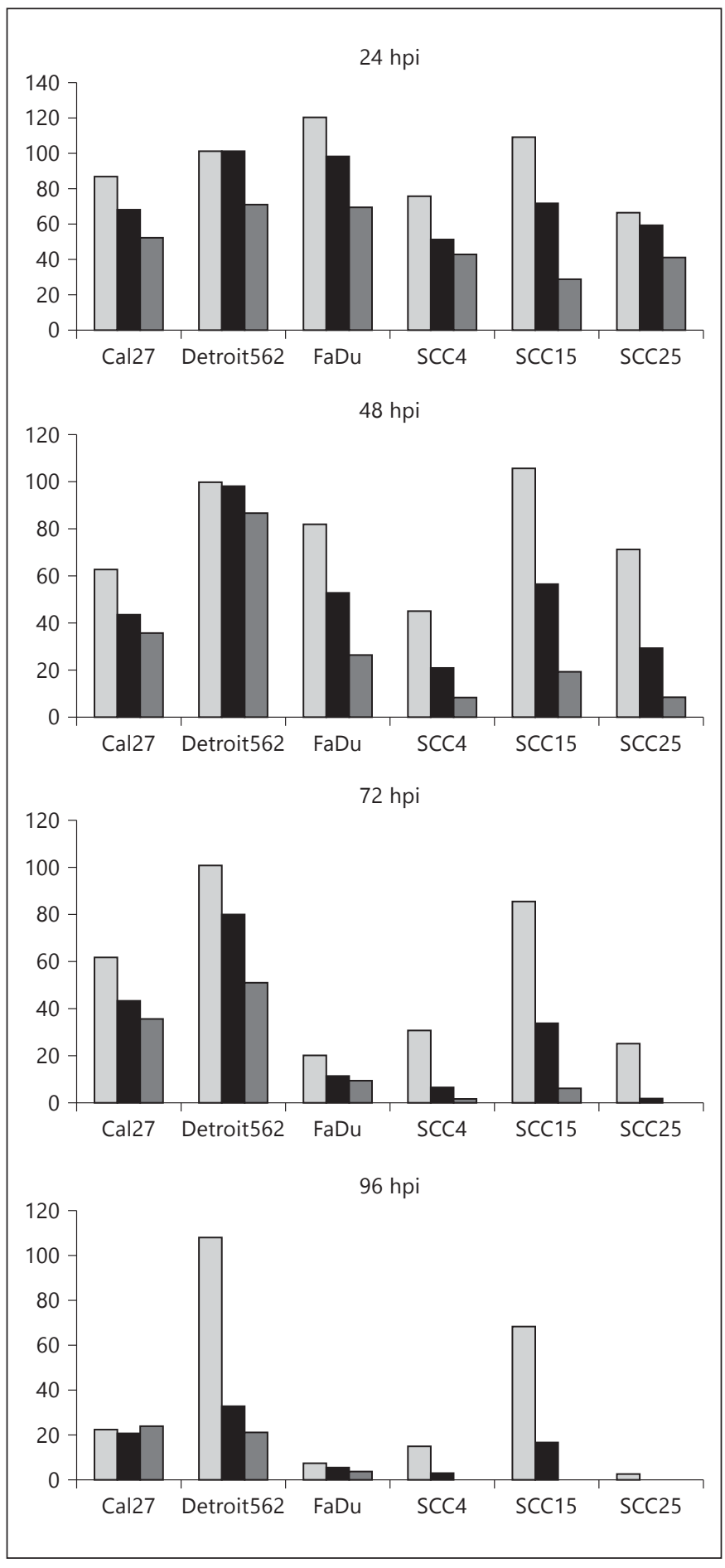

Fig. 3. VACV was an effective oncolytic in a time- and dose-dependent manner in HNSCC lines. Proliferation of the six HNSCC cell lines were evaluated at 24, 48, 72 and $96 \mathrm{~h}$ either untreated or following VACV infection at MOI $=0.03,0.3$, 3. Fluorescence values (relative fluorescence units; RFU) as a measure of cell numbers were compared against the uninfected controls and blanks to determine the percent metabolic activity and plotted on the Y-axis. The $\mathrm{X}$-axis represents the cell lines. 
ways. Cancer is derived from accumulation of oncogene activation (e.g. h-ras or PIK3CA) and tumor suppressor (e.g. p53, Rb) gene inactivation. Together the combination of tumor suppressor mutation and oncogene activation may dictate virus tropism [17]. As a large number of HNSCC cell lines have now been genetically characterized $[18,19]$, screening a large panel of these lines with an expanded panel of oncolytic viruses could potentially provide mutational markers of viral efficacy and resistance. This would allow application of a particular virus for a given tumor genotype in order to obtain an optimal response. Given the limited toxicity of oncolytic therapy [2], if poxviruses prove to be effective it would be a tremendous step toward improving the quality as well as quantity of life for patients suffering with HNSCC.

\section{Conclusion}

Our in vitro screen of oncolytic poxviruses for the control of HNSCC has revealed varying efficacy between cell lines, however vaccinia (VACV) virus was the most potent and broadly effective. Further study is necessary to understand the mechanisms of oncolytic virus resistance. Poxvirus virotherapy offers hope for improved survival and decreased toxicity in HNSCC.

\section{Acknowledgement} Fund.

\section{References}

1 Ferlay J, Shin HR, Bray F, Forman D, Mathers C, Parkin DM: Estimates of worldwide burden of cancer in 2008: GLOBOCAN 2008. Int J Cancer 2010;127:2893-2917.

-2 Russell SJ, Peng KW, Bell JC: Oncolytic virotherapy. Nat Biotechnol 2012;30:658-670.

- 3 Bais S, Bartee E, Rahman MM, McFadden G, Cogle CR: Oncolytic virotherapy for hematological malignancies. Adv Virol 2012;2012: 186512.

-4 Evgin L, Vaha-Koskela M, Rintoul J, Falls T, Le Boeuf F, Barrett JW, Bell JC, Stanford MM: Potent oncolytic activity of raccoonpox virus in the absence of natural pathogenicity. Mol Ther 2010;18:896-902.

5 McFadden G: Poxvirus tropism. Nat Rev Microbiol 2005;3:201-213.

6 Villa NY, Bartee E, Mohamed MR, Rahman MM, Barrett JW, McFadden G: Myxoma and vaccinia viruses exploit different mechanisms to enter and infect human cancer cells. Virology 2010;401:266-279.

7 Tysome JR, Wang P, Alusi G, Briat A, Gangeswaran R, Wang J, Bhakta V, Fodor I, Lemoine NR, Wang Y: Lister vaccine strain of vaccinia virus armed with the endostatin-angiostatin fusion gene: an oncolytic virus superior to d11520 (ONYX-015) for human head and neck cancer. Hum Gene Ther 2011;22:11011108.

8 Yu Z, Li S, Brader P, Chen N, Yu YA, Zhang Q, Szalay AA, Fong Y, Wong RJ: Oncolytic vaccinia therapy of squamous cell carcinoma. Mol Cancer 2009;8:45.

-9 Nichols AC, Yoo J, Palma DA, Fung K, Franklin JH, Koropatnick J, Mymryk JS, Batada NN, Barrett JW: Frequent mutations in TP53 and CDKN2A found by next-generation sequencing of head and neck cancer cell lines. Arch Otolaryngol Head Neck Surg 2012;138:732739.
10 Campbell S, Hazes B, Kvansakul M, Colman P, Barry M: Vaccinia virus F1L interacts with Bak using highly divergent Bcl-2 homology domains and replaces the function of Mcl-1. J Biol Chem 2010;285:4695-4708.

11 Johnston JB, Barrett JW, Chang W, Chung CS, Zeng W, Masters J, Mann M, Wang F, Cao J, McFadden G: Role of the serine-threonine kinase Pak-1 in myxoma virus replication. J Virol 2003;77:5877-5888.

12 Nazarian SH, Barrett JW, Stanford MM, Johnston JB, Essani K, McFadden G: Tropism of tanapox virus infection in primary human cells. Virology 2007;368:32-40.

13 Kirn DH, Thorne SH: Targeted and armed oncolytic poxviruses: a novel multi-mechanistic therapeutic class for cancer. Nat Rev Cancer 2009;9:64-71.

14 Foloppe J, Kintz J, Futin N, Findeli A, Cordier $\mathrm{P}$, Schlesinger Y, Hoffmann C, Tosch C, Balloul JM, Erbs P: Targeted delivery of a suicide gene to human colorectal tumors by a conditionally replicating vaccinia virus. Gene Ther 2008;15:1361-1371.

15 Mansfield D, Pencavel T, Kyula JN, Zaidi S, Roulstone V, Thway K, Karapanagiotou L, Khan AA, McLaughlin M, Touchefeu Y, Seth R, Melcher AA, Vile RG, Pandha HS, Harrington $\mathrm{KJ}$ : Oncolytic vaccinia virus and radiotherapy in head and neck cancer. Oral Oncol 2013;49:108-118.

16 Saito K, Shirasawa H, Isegawa N, Shiiba M, Uzawa K, Tanzawa H: Oncolytic virotherapy for oral squamous cell carcinoma using replication-competent viruses. Oral Oncol 2009; 45:1021-1027.
17 Kim M, Williamson CT, Prudhomme J, Bebb DG, Riabowol K, Lee PW, Lees-Miller SP, Mori Y, Rahman MM, McFadden G, Johnston RN: The viral tropism of two distinct oncolytic viruses, reovirus and myxoma virus, is modulated by cellular tumor suppressor gene status. Oncogene 2010;29:3990-3996.

18 Barretina J, Caponigro G, Stransky N, Venkatesan K, Margolin AA, Kim S, Wilson CJ, Lehar J, Kryukov GV, Sonkin D, Reddy A, Liu M, Murray L, Berger MF, Monahan JE, Morais P, Meltzer J, Korejwa A, Jane-Valbuena J, Mapa FA, Thibault J, Bric-Furlong E, Raman P, Shipway A, Engels IH, Cheng J, Yu GK, Yu J, Aspesi P Jr, de Silva M, Jagtap K, Jones MD, Wang L, Hatton C, Palescandolo E, Gupta S, Mahan S, Sougnez C, Onofrio RC, Liefeld T, MacConaill L, Winckler W, Reich M, Li N, Mesirov JP, Gabriel SB, Getz G, Ardlie K, Chan V, Myer VE, Weber BL, Porter J, Warmuth M, Finan P, Harris JL, Meyerson M, Golub TR, Morrissey MP, Sellers WR, Schlegel R, Garraway LA: The cancer cell line encyclopedia enables predictive modelling of anticancer drug sensitivity. Nature 2012;483:603-607.

19 Garnett MJ, Edelman EJ, Heidorn SJ, Greenman CD, Dastur A, Lau KW, Greninger P, Thompson IR, Luo X, Soares J, Liu Q, Iorio F, Surdez D, Chen L, Milano RJ, Bignell GR, Tam AT, Davies H, Stevenson JA, Barthorpe S, Lutz SR, Kogera F, Lawrence K, McLarenDouglas A, Mitropoulos X, Mironenko T, Thi H, Richardson L, Zhou W, Jewitt F, Zhang T, O'Brien P, Boisvert JL, Price S, Hur W, Yang W, Deng X, Butler A, Choi HG, Chang JW, Baselga J, Stamenkovic I, Engelman JA, Sharma SV, Delattre O, Saez-Rodriguez J, Gray NS, Settleman J, Futreal PA, Haber DA, Stratton MR, Ramaswamy S, McDermott U, Benes $\mathrm{CH}$ : Systematic identification of genomic markers of drug sensitivity in cancer cells. $\mathrm{Na}$ ture 2012;483:570-575. 